\title{
A questão ambiental e a formação de professores para a educação básica: um olhar sobre as licenciaturas
}

\section{The environmental issue and teachers' training for basic education: a look at undergraduate courses}

\author{
Cristina Teixeira ${ }^{1}$ \\ Marília Andrade Torales ${ }^{1}$
}

\begin{abstract}
RESUMO
Nas últimas décadas foi possível acompanhar a expansão da temática ambiental em diferentes campos de formação e pesquisa. É crescente o número de cursos de graduação e pós-graduação, disciplinas específicas, projetos de extensão e pesquisa que se dedicam a problematizar e a buscar soluções para os problemas ambientais enfrentados pela sociedade contemporânea. Este cenário estabelece desafios para a gestão, a pesquisa e a formação de estudantes no Ensino Superior. Ele exige uma sólida argumentação e o desenvolvimento de pesquisas sobre o conhecimento ambiental como parte da formação dos futuros profissionais de nível superior, dentre eles, o professor da educação básica. O desenvolvimento de políticas públicas para a educação ambiental no Brasil introduziu a educação ambiental nas escolas desde os anos 1990. São leis, diretrizes, programas e projetos que tratam de matérias que vão desde diretrizes curriculares até a construção de "escolas sustentáveis". Como os cursos de licenciatura estão preparando os futuros professores para esta institucionalização da educação ambiental? Este artigo apresenta os resultados de uma pesquisa exploratória sobre ações formativas que consideram a dimensão ambiental nos cursos de licenciatura da Universidade Federal do Paraná (UFPR). Nesta análise foram consideradas as características teóricas e epistemológicas desse conhecimento e as condições institucionais de seu desenvolvimento na universidade, que,
\end{abstract}

DOI: $10.1590 / 0104-4060.38111$

1 Universidade Federal do Paraná. Setor de Educação. Curitiba, Paraná, Brasil. Rua General Carneiro, $\mathrm{n}^{\circ}$ 460. CEP: 80060-150. 
em última instância, condicionam as possibilidades de desenvolvimento da dimensão ambiental na formação dos licenciandos.

Palavras-chave: educação ambiental; licenciatura; formação de professores.

\begin{abstract}
In the last decades it was possible to follow the expansion of environmental issues in different fields of training and research. The number of undergraduate and graduate courses, specific subjects, research and extension projects that are dedicated to question and to seek solutions to the environmental problems faced by contemporary society is increasing. This scenario establishes challenges for the management, research and training of students in Higher Education. It requires solid argumentation and the development of research on environmental knowledge as part of the training of future professionals in Higher Education, among them, the basic education teacher. The development of public policies for environmental education in Brazil has introduced environmental education in schools since the 1990s. These include laws, policies, programs and projects about issues ranging from curriculum guidelines to building "sustainable schools". How are the undergraduate programs preparing future teachers for this institutionalization of environmental education? This article presents the results of an exploratory research on training activities that consider the environmental issue in undergraduate courses at the Federal University of Paraná (UFPR). This analysis considered the theoretical and epistemological characteristics of this knowledge and the institutional conditions of its development at the university, which ultimately affect the possibilities of development of the environmental dimension in the training of undergraduates.
\end{abstract}

Keywords: environmental education; undergraduate courses; teacher training.

\title{
Introdução
}

Em junho de 2012 foram definidas as Diretrizes Curriculares Nacionais para a Educação Ambiental, dando continuidade ao movimento de institucionalização da educação ambiental no país iniciado nos anos 1990 com a Política Nacional de Educação Ambiental (PNEA). As Diretrizes reafirmam a presença da educação ambiental em todos os níveis de ensino, já presente na PNEA e na própria Constituição Federal brasileira. Este movimento intensificou a inserção da educação ambiental nas escolas, conforme consta nos Parâmetros Curriculares Nacionais (BRASIL, 1997). Nesse contexto se torna mais evidente a necessidade 
de capacitação dos professores e destaca-se o terceiro objetivo das Diretrizes, que é "a formação dos docentes para a Educação Básica".

A reflexão e a prática da educação ambiental não são resultados exclusivos das políticas públicas. Todavia, elas estabelecem as orientações e impulsionam projetos, programas, formação continuada de professores, material didático e outras estratégias, com maior ou menor sistematização e sucesso, para desenvolver a educação ambiental nas instituições de ensino, inclusive nos cursos de formação de professores nas universidades. Embora a educação ambiental se expanda, ela ainda é pouco abrangente e se caracteriza por ações pontuais e incipientes como prática a ser potencializada (TORALES, 2013).

Há cerca de uma década, no Brasil, o debate e os estudos sobre ambientalização curricular e ambientalização das universidades (GUERRA, 2013; PAVESI; FARIAS; OLIVEIRA, 2006), ao lado dos inúmeros relatos de experiências de educação ambiental, revelam que ela está presente em todos os níveis de ensino. Indicam também que as práticas ainda tergiversam sobre os fundamentos da educação ambiental ao simplificarem a complexidade da questão ambiental e as reflexões que ela instiga. Consequentemente, reduz-se ou elimina-se o potencial transformador presente nos princípios que definem sua identidade político-pedagógica, construída a partir da crítica à sociedade moderna, e a relação que ela estabelece com a natureza (CARVALHO, 2004; LIMA, 2011; TORALES, 2013).

O professor é o responsável pela execução da educação ambiental e o faz a partir de seus conhecimentos, representações e intencionalidades no que se refere à educação e à problemática ambiental (TORALES, 2013). Diante do avanço da educação ambiental na educação básica, o professor é colocado diante de exigências às quais ele responde com dificuldade e para as quais os cursos de licenciatura pouco contribuem. Certo distanciamento dos professores da educação ambiental tem como justificativa desde condições de trabalho que dificultam inovações e mais esforços, até a constatação de que não estão preparados para trabalhar com a educação ambiental. Este artigo analisa esta preparação nos cursos de licenciatura da Universidade Federal do Paraná (UFPR), na qual ela é realizada principalmente por disciplinas de "educação ambiental", objeto desta análise. Foi realizada uma caracterização destas disciplinas em seus aspectos político-epistemológicos, uma vez que estes condicionarão o olhar dos professores sobre os sentidos da educação ambiental. Como estas características fazem parte de um processo mais amplo de construção de novos bens simbólicos na universidade, elas serão analisadas a partir de alguns aspectos do conceito

2 Entende-se por disciplinas de Educação Ambiental aquelas que consideram a dimensão educativo-ambiental em sua ementa ou na relação de conteúdos. 
de campo de Bourdieu (2004), particularmente da ideia de desconfiguração provocada pela refração do campo. As características encontradas reafirmam o potencial transformador da educação ambiental ou a refração do campo desconfigurou esta utopia?

\section{A construção do campo educativo-ambiental e o compromisso com a sociedade}

A presença da educação ambiental nas licenciaturas é a extensão do processo de retradução da crise ambiental no campo acadêmico na forma de problemática ambiental. Na definição de Bourdieu (1983), o campo é o locus estruturado de posições disputadas pelos agentes sociais que o constitui. Estes agentes lutam pela apropriação, ou a redefinição, de um capital específico ao campo, desigualmente distribuído. Esta luta se caracteriza por subversão e conservação das posições de poder e do capital pertinentes a este campo, que possui sua lógica interna, ainda que subordinada, em maior ou menor grau, às lutas econômicas, sociais e políticas que estruturam o espaço social.

Ao abordar a origem do conceito de campo, Bourdieu afirma que ele foi elaborado para resolver um problema colocado pela explicação da produção dos bens simbólicos na sociedade. A produção cultural, na qual se incluem a ciência e o conhecimento ambiental, se explica pela articulação entre o seu conteúdo, na forma de autoexplicação - uma obra se explica por si só - e as suas determinações sociais. Ela está sujeita ao contexto social no qual foi produzida e, portanto, a explica. Estas duas determinações se articulam no campo, o universo intermediário que "é um mundo social como os outros, mas que obedece a leis sociais mais ou menos específicas" (BOURDIEU, 2004, p. 20). Neste sentido, o campo é um espaço relativamente autônomo, com leis próprias, ainda que na produção ele se constitua em função das pressões e solicitações externas a ele, por exemplo, aquelas colocadas pela questão ambiental à formação acadêmica. A reação do campo às pressões e solicitações varia de acordo com o seu grau de autonomia: "quanto mais autônomo for um campo, maior será o seu poder de refração e mais as imposições externas serão transfiguradas, a ponto, frequentemente, de se tornarem perfeitamente irreconhecíveis" (BOURDIEU, 2004 , p. 21, 22). O quanto o conhecimento ambiental tem sido transfigurado para garantir sua permanência na universidade?

O campo acadêmico possui significativa autonomia, portanto forte poder de refração. Isto é garantido com a particularidade de considerar que o interesse 
científico está acima das lutas internas, criando a falsa ideia de uma produção e reprodução de um capital desinteressado. Para legitimar o desinteresse, as estratégias adotadas por esse campo fazem com que "as pressões sociais assumam a forma de pressões lógicas, e reciprocamente; para se fazer valer aí, é preciso fazer valer razões; para aí triunfar, é preciso fazer triunfar argumentos, demonstrações e refutações" (BOURDIEU, 2004, p. 32). A produção de novos bens simbólicos e o seu valor no campo acadêmico depende de um processo de "convencimento", segundo procedimentos específicos ditados pelo conhecimento científico.

Isso é realizado pelos agentes do campo que lutam para conservar ou transformar as forças que o constituem, nele criando espaços. O fazem a partir de uma posição no campo que condiciona as possibilidades de sucesso nesta luta. Bourdieu (2004, p. 23) utiliza o exemplo de Einstein que: "[...] deformou todo o espaço em torno de si. Essa metáfora 'einsteiniana' a propósito do próprio Einstein significa que não há físico, pequeno ou grande, em Brioude ou em Harvard que (independente de qualquer contato direto, de qualquer interação) não tenha sido tocado, perturbado, marginalizado pela intervenção de Einstein". Para o conhecimento ambiental na universidade, os pesquisadores e professores foram os responsáveis por sua trajetória em meio as estruturas objetivas do campo, criando assim os espaços de pertencimento ao campo.

Esse processo está presente no caso dos "bens simbólicos" produzidos a partir da constatação de uma crise ambiental e da problemática que ela institui sobre suas causas e soluções e a relação destas com a maneira como a sociedade se relaciona com a natureza. Dentre os diferentes discursos sobre esta questão, aqueles que causam perturbação ao campo acadêmico são as reflexões sobre a reconstrução do conhecimento científico que dá forma e sentido ao campo acadêmico.

A crise ambiental se apresenta na forma de "rupturas e articulação científico-conceituais, simbólico-ideológicas e político-econômicas" (CARNEIRO, 2006, p. 24) nas quais se constrói "uma nova visão do mundo que transforma os paradigmas do conhecimento teórico e os saberes práticos" (LEFF, 2006, p. 279) numa espécie de revisão de racionalidades e paradigmas que regem a relação entre a sociedade e a natureza. Leff (2006), Morin, Ciurana e Motta (1992) e Santos (1989) fazem referência a um novo paradigma do conhecimento ou a uma nova racionalidade que considere a realidade complexa que deve ser apreendida pelo pensamento complexo, capazes de balançar as fronteiras entre ciências e entre a ciência e outras formas de conhecimento, revendo, assim, os fundamentos da ciência moderna. A cultura técnico-científica, cuja racionalidade que a fundamenta é a racionalidade instrumental, econômica, capitalista-industrial e tecnológica, reduziu a complexidade da realidade através do determinismo e 
do mecanicismo dos fenômenos físicos e naturais. Esta cultura corresponde à fragmentação e à coisificação do mundo em função da busca do seu controle, necessário para atender aos interesses de uma civilização que "economicizou o mundo" (LEFF, 2006, p. 288). Leff $(2006,2007)$ propõe a construção do conhecimento sob a ótica de uma racionalidade ambiental que coloca as condições para a formação de um saber ambiental, considerado como um processo em construção capaz de conhecer a complexidade ambiental.

A utopia da construção de nova racionalidade ou do saber ambiental se encontra em cursos, projetos de pesquisa, eventos acadêmicos, currículos e outros processos educativos na universidade. Na trajetória de um novo bem simbólico no campo, estratégias são acionadas para assegurar a sua reprodução. Se hoje um "saber ambiental" ganha espaço e está nos cursos de formação universitária, é porque, ao reconhecer as regras do campo, fez valer suas razões em meio às disputas de argumentos de legitimação.

Sobre a construção do campo educativo-ambiental, Leff (2013) afirma em entrevista concedida a Miguel Angél Arias Ortega que "no campo da educação existem alguns problemas burocráticos, sindicais, éticos, da vocação própria do educador; mas também a instituição educativa tem sido funcional a essa realidade" (LEFF, 2013, p. 42), tendo em vista que esta estabelece suas prioridades em relação à sociedade.

Esta indissociabilidade entre a sociedade, o conhecimento e a educação instiga os mesmos autores da revisão de racionalidades ou paradigmas acima citados a refletirem sobre mudanças necessárias à educação para que esta articule a mudança do conhecimento, citando nestes casos a mudança da relação entre a sociedade e a natureza (LEFF, 2007; MORIN; CIURANA; MOTTA, 2003; SANTOS, 2008). Leff (2007, p. 18), por exemplo, considera necessária a fundação de uma pedagogia ambiental. Esta se desloca da função adaptativa da educação para uma realidade regida pela racionalidade dominante, para uma formação capaz de lidar com as incertezas do mundo atual através da criação de novas possibilidades de enfrentar os problemas colocados pela crise ambiental. Para isto, a educação deve se orientar pela imaginação criativa, pela utopia de uma nova racionalidade e de um novo saber.

\section{A utopia e a realidade do debate em relação à educação ambiental}

A utopia da construção de uma nova racionalidade, de um novo paradigma, da mudança civilizacional, permanece no horizonte de formação intelectual, 
moral e política de sujeitos e se reflete na educação ambiental desde suas origens. Para Carvalho (2004), a educação ambiental está vinculada à crítica radical da sociedade responsável pela crise ambiental, da qual a relação do homem e da sociedade com a natureza não se dissocia.

Os discursos e o debate sobre a crise ambiental podem seguir diferentes abordagens político-epistemológicas no campo ambiental, as quais correspondem às diferentes concepções e práticas da educação ambiental (LIMA, 2011). Estas se diferenciam de acordo com a perspectiva de relação entre a sociedade e a natureza, o entendimento da crise ambiental e suas soluções, a necessidade de reconstrução de um saber ambiental, as possibilidades de construção de novas visões de mundo diante da problemática ambiental e sua relação com a educação e metodologias de ensino-aprendizagem. Diferenciam-se ainda de acordo com as concepções de educação de abordagens didático-pedagógicas tout court.

Para Sauvé (2005, p. 317), "o objeto da educação ambiental é de fato, fundamentalmente, nossa relação com o meio ambiente". Para executá-la, diferentes dimensões educacionais se articulam - intelectual, moral, social, política, estética, etc. - visando à compreensão da complexidade que caracteriza essa realidade e o seu conhecimento, ambos distorcidos pela racionalidade instrumental, econômica, capitalista-industrial e tecnológica, que separou a sociedade da natureza. A reintegração que a complexidade evidencia marca o potencial transformador da educação ambiental. Por sua vez, a transformação depende da formação do sujeito ecológico (CARVALHO, 2004) ou do cidadão ambiental (GONZÁLEZ-GAUDIANO, 2003, p. 611) que "implica una pedagogía social, que se propone desarrollar competencias para vivir de un modo que implica la capacidad deliberada de saber elegir entre varias opciones, a partir de consideraciones éticas e intereses comunitarios, esto es, políticos". Novamente se observa a indissociabilidade entre a sociedade, o conhecimento e a educação.

No âmbito nacional, desde a Política Nacional de Educação Ambiental (PNEA), de 1999, até as Diretrizes Curriculares para a Educação Ambiental de 2012, que deverão orientar a educação ambiental em todos os níveis de ensino, foram 10 anos de discussões sobre a institucionalização da educação ambiental. Nesta tessitura, ora ressaltam sua dimensão reprodutora das condições socioambientais que caracterizam a crise ambiental, por exemplo, o discurso da educação ambiental para o desenvolvimento sustentável (CARVALHO, 2004; SAUVÉ, 2005), ora se aliam ao discurso da educação ambiental crítica e emancipatória como é o caso das Diretrizes de 2012 (CRUZ; BIGLIARDI, 2012), embora no documento as palavras "mudança" e "transformação" são substituídas por "construção de sociedades justas e sustentáveis".

Assim como a PNEA, as Diretrizes mantêm a "compreensão integrada do meio ambiente em suas múltiplas e complexas relações para fomentar novas 
práticas sociais e de produção e consumo" (BRASIL, 2012, p. 4). Para isto, propõem novas relações disciplinares através de "prática educativa integrada e interdisciplinar" (BRASIL, 2012, p. 3), além da "abordagem curricular integrada e transversal, contínua e permanente em todas as áreas de conhecimento, componentes curriculares e atividades escolares e acadêmicas" (BRASIL, 2012, p. 4).

As políticas impõem ou estimulam iniciativas de educação ambiental como, por exemplo, a introdução da temática ambiental no currículo do ensino básico através dos Parâmetros Curriculares Nacionais (PCNs), cursos de formação continuada de professores, financiamentos para projetos de educação ambiental e programa de construção de escolas sustentáveis, dentre outras. Em todas elas há uma perspectiva de educação ambiental subjacente, assim como nas atividades formativas que se desenvolvem nos cursos de licenciatura.

\section{A educação ambiental na formação dos professores na UFPR}

O conhecimento ambiental está presente nas universidades brasileiras desde o final dos anos 1980, e tem sido objeto de análise, cujas conclusões confirmam a presença da temática ambiental no ensino, na pesquisa, na extensão e na gestão, na graduação e na pós-graduação, através de diferentes abordagens teóricas e metodológicas. Neste processo de "ambientalização de disciplinas" e "interdisciplinarização" do ambiente (BURSZTYN, 2004), a temática ambiental se dissipa nas instituições de ensino superior, mas com dificuldades para inserir as mudanças no conhecimento que ela carrega. Por exemplo, ao estabelecer novas relações entre disciplinas, encontra a resistência da organização do conhecimento no ensino superior em unidades, departamentos e disciplinas que isolam conhecimentos (BURSZTYN, 2004; OLIVEIRA, 2011; RUPEA, 2005; THOMAZ; CAMARGO, 2007; VISÕES..., 2011).

Além da formação ofertada nas instituições de ensino superior, outros espaços dentro do campo acadêmico são ocupados por esse conhecimento, tais como eventos e publicações científicas, indicando que ele tem conseguido fazer "triunfar argumentos, demonstrações e refutações" de acordo com as regras do campo. Contudo, ainda são "focos" que não garantem a sua vitória na disputa pelo poder no campo. De certa forma, a imagem que mais se aproxima desta possibilidade tem sido apresentada pelo discurso da ambientalização do Ensino Superior, na qual haveria 
o questionamento, a depuração e evolução de conceitos, teorias e métodos das ciências/disciplinas e a abertura de seus objetos de interesse a uma perspectiva ambiental, interdisciplinar, transdisciplinar e complexa; a redefinição dos perfis profissionais e dos currículos (em seus conteúdos, formatos e práticas), com a previsão de novos espaços e oportunidades de formação discente e docente; a reformulação dos conhecimentos e saberes dos docentes/pesquisadores (e sua integração em uma formação interdisciplinar), bem como dos valores inerentes à ação formativa; a construção e aplicação de critérios e indicadores ambientais que permitam acompanhar e/ou redirecionar as atividades de gestão/administração das Instituições de Ensino Superior (IES) (PAVESI; FARIAS; OLIVEIRA, 2006, p. 1).

O que se observa na UFPR corrobora com estudos e observações sobre a presença do conhecimento ambiental na universidade (TEIXEIRA, 2011). Ainda assim, a análise da educação ambiental nos cursos de licenciatura contribui para ampliar a compreensão da trajetória do conhecimento ambiental no campo acadêmico. Mais especificamente, contribui para a compreensão da trajetória das referências político-epistemológicas que ela veicula nos cursos de formação de professores para a educação básica e da tradução que estas referências sofrem ao ocuparem seu espaço no campo.

Nos cursos de licenciatura da UFPR, a presença da temática ambiental é menos expressiva do que nos cursos de bacharelado. Considerando somente a presença de disciplinas com o atributo ambiental, estas estão mais presentes nos bacharelados do que nas licenciaturas. Nas licenciaturas foram encontradas seis disciplinas com este perfil, enquanto nos bacharelados são cerca de 15, nas quais algumas podem ser cursadas por alunos de licenciatura. São disciplinas que não possuem nenhuma relação com a educação ambiental, mas que têm sua importância na formação do conhecimento ambiental, como é o caso da disciplina "Ciências do Ambiente" , optativa para Ciências Biológicas (Campus Curitiba), e "Sociedade, Espaço e Natureza"4, obrigatória para Ciências Sociais. Temas como a crise ambiental, novos paradigmas do conhecimento, por exemplo, constam dos programas destas disciplinas.

3 AZ027 - Ciências do Ambiente. Plano de Ensino. Disponível em: $<$ http://www.bio.ufpr. br/portal/cbio/wp-content/uploads/sites/3/2013/04/AZ027.pdf>. Acesso em: 05/05/2014.

4 HC326 - Sociedade, Espaço e Natureza. Plano de Ensino. Disponível em: <http://www.humanas.ufpr.br/portal/cienciassociais/files/2014/01/HC326-Sociedade-Espa\%C3\%A7o-e-Natureza. pdf $>$. Acesso em: 05/06/2014. 
A opção por analisar as disciplinas voltadas à educação ambiental se justifica pelo fato de representarem as ações educativas em maior número, além de envolverem uma quantidade de alunos maior do que as outras atividades formativas. Na UFPR, em 2014, encontramos cinco projetos sobre educação ambiental com a participação de 26 alunos (Cinco Projetos de Pesquisa com cinco alunos, um Projeto de Extensão com sete alunos e um Projeto de Iniciação à Docência (PIBID) com 14 alunos), enquanto que mais de 100 alunos cursaram disciplinas que abordam a educação ambiental, mas sem envolvimento com outras ações fora do âmbito do ensino.

A UFPR possui 22 cursos de licenciatura distribuídos em quatro campi e um curso na modalidade a distância. Seis cursos possuem uma disciplina obrigatória voltada à educação ambiental: Ciências (Campus Matinhos); Ciências Biológicas (Campus Curitiba e Campus Palotina); Ciências Exatas (Campus Pontal e Campus Palotina); Artes Visuais, Filosofia, Geografia e Química (Campus Curitiba). Um deles, Ciências Biológicas (Campus Curitiba) possui duas destas disciplinas. Há somente uma disciplina optativa, Meio Ambiente e Educação, ofertada para dois cursos de licenciatura: Ciências Biológicas e Pedagogia presencial, ambos ofertados no Campus Curitiba. Com exceção desta última disciplina, criada há cerca de 10 anos, as demais foram criadas a partir de 2008, duas delas em 2013, acompanhando as reformulações curriculares ou a criação de novos cursos nos quais a dimensão ambiental foi incluída em seus projetos pedagógicos. Para a licenciatura em Ciências Exatas, por exemplo, a formação tem "uma visão do papel do educador que valorize e construa o conhecimento em face da educação ambiental", o que denota uma inovação na própria base pedagógica e na proposta formativa do curso.

As disciplinas obrigatórias que abordam a educação ambiental nas licenciaturas são: "Vivências de Docência, Relação Ciências e Meio Ambiente e Prática de Ensino"s; "Fundamentos da Educação Ambiental";; "Educação Ambiental (1)" e "Educação Ambiental (2)" ". A primeira delas não é uma disciplina voltada à educação ambiental, mas abriga em um dos seus itens este assunto. No caso de Educação Ambiental, embora com o mesmo nome, são disciplinas de cursos

5 UNIVERSIDADE FEDERAL DO PARANÁ. SETOR LITORAL. Projeto Pedagógico de Curso Licenciatura em Ciências. Disponível em: <http://www.litoral.ufpr.br/sites/default/files/ PPC_LicCiencias_junho_2011.pdf >. Acesso em: 05/05/2014.

6 ET076 - Fundamentos da Educação Ambiental. Plano de Ensino. Disponível em: $<$ http://www.bio.ufpr.br/portal/cbio/wp-content/uploads/sites/3/2013/04/ET076.pdf $>$. Acesso em: 05/05/2014.

7 UNIVERSIDADE FEDERAL DO PARANÁ. SETOR PALOTINA. Projeto Político Pedagógico do curso de Licenciatura em Ciências Exatas. Disponível em: $<$ http://www.campuspalotina. ufpr.br/sites/default/files/ PPCEXATASPALOTINA.pdf>. Acesso em: 05/06/2014. 
diferentes, com cargas horárias diferentes e serão ofertadas pela primeira vez somente no próximo ano. Para o curso de Ciências Exatas, nos dois campus diferentes, a disciplina tem o mesmo programa. Mais uma disciplina obrigatória "Estágio Supervisionado em Processos Interativos da Educação", obrigatória para oito licenciaturas, também não é disciplina específica para a educação ambiental. Contudo, ela permite que o professor escolha o tema do estágio. Em cinco turmas desta disciplina o tema da educação ambiental foi escolhido.

As disciplinas Fundamentos da Educação Ambiental, Estágio Supervisionado e Meio Ambiente e Educação são ofertadas pelo Setor de Educação. As demais, por seus próprios cursos.

TABELA 1 - DISCIPLINAS DE EDUCAÇÃO AMBIENTAL POR CURSO E CARGA HORÁRIA

\begin{tabular}{llc}
\hline Disciplina & Curso de Licenciatura em & Carga \\
\hline $\begin{array}{l}\text { Vivências de docência, relação } \\
\text { Ciências e Meio Ambiente e } \\
\text { prática de ensino }\end{array}$ & Ciências (Campus Matinhos) & $160 \mathrm{~h} / \mathrm{a}$ \\
$\begin{array}{l}\text { Fundamentos da Educação } \\
\text { Ambiental }\end{array}$ & Ciências Biológicas (Campus Curitiba) & $90 \mathrm{~h} / \mathrm{a}$ \\
Educação Ambiental & Ciências Biológicas (Campus Palotina) & \\
Educação Ambiental & $\begin{array}{l}\text { Ciências Exatas (Campus Pontal) } \\
\text { Ciências Exatas (Campus Palotina) }\end{array}$ & $36 \mathrm{~h} / \mathrm{a}$ \\
$\begin{array}{l}\text { Estágio em Processos } \\
\text { Interativos da Educação }\end{array}$ & $\begin{array}{l}\text { Artes Visuais (Campus Curitiba) } \\
\text { Ciências Biológicas (Campus Curitiba) }\end{array}$ & $120 \mathrm{~h} / \mathrm{a}$ \\
& $\begin{array}{l}\text { Filosofia (Campus Curitiba) } \\
\text { Geografia (Campus Curitiba) } \\
\text { Química (Campus Curitiba) } \\
\text { (optativa) }\end{array}$ & Ciências Biológicas (Campus Curitiba) \\
\hline
\end{tabular}

FONTE: Elaboração própria.

As disciplinas refletem as pressões sociais sobre o campo para atender a uma solicitação a ele colocada, no caso, a formação de professores para o exercício de uma ação educativo-ambiental. Essas pressões são transmutadas pelos agentes do campo, no caso os professores que criaram e ministram estas disciplinas. Na UFPR, os cinco professores que criaram ou se ocupam destas disciplinas possuem formação e pesquisa vinculados à temática ambiental, mas somente um deles possui doutorado e pesquisa sobre Educação Ambiental.

8 ET054 - Estágio Supervisionado em Processos Interativos da Educação. Plano de Ensino. 
Isto reflete a trajetória dos bens simbólicos na universidade, de forma geral, no movimento que parte da Pesquisa ao Ensino.

A opção por trabalhar através de disciplina tradicional, o que não é recomendado por estudos e políticas públicas de educação ambiental, reflete a estratégia de garantir a sua presença, mesmo que seja necessário transfigurá-la, exemplificando a refração que o campo exerce sobre os bens simbólicos. Outras opções estratégicas exigiriam "esforço" pessoal, coletivo e institucional na luta para fazer valer o capital simbólico, que os agentes não realizaram. Deve-se considerar ainda que, hipoteticamente, estes agentes não ocupam posições dominantes no campo, o que torna ainda maior o esforço nas estratégias para fazer valer o bem simbólico.

Um aspecto importante a ser observado nas disciplinas é a carga horária. Aquelas que possuem maior carga horária são disciplinas de estágio, sem espaço para grandes inserções em conteúdos teóricos. As duas com cerca de 30h/a possuem o mesmo problema, agora dado o seu curto período de tempo para fazê-lo. Somente a disciplina de Fundamentos da Educação Ambiental possui um tempo confortável para o desenvolvimento de seu conteúdo.

Para a construção do perfil político-epistemológico das disciplinas, foram analisados a ementa, o programa e a bibliografia de cada uma delas. Foram definidos assuntos possíveis de serem identificados no "conteúdo" da disciplina que pudessem indicar direta ou indiretamente, de forma exploratória, os aspectos relacionados à sua orientação político-epistemológica, tomando como referência as considerações deste artigo sobre o assunto. São eles: 1) Histórico da educação ambiental, pois nele, geralmente, estão contidas características teóricas e metodológicas da educação ambiental; 2) As políticas públicas para a educação ambiental, pelo mesmo motivo; 3 ) A heterogeneidade da educação ambiental, pois neste assunto se encontram as diferentes possibilidades de abordagem político-epistemológica da educação ambiental; 4) A transformação de racionalidade ou paradigma do conhecimento para enfrentar a problemática ambiental e a decorrente relação entre disciplinas e saberes, 5) A mudança social como mudança da relação entre a sociedade e a natureza em suas dimensões econômica, política e cultural, considerada também uma mudança civilizacional.

O histórico da educação ambiental está presente em quase todas as disciplinas analisadas, exceto em "Vivências de Docência", que não tem a educação ambiental como foco, mas apenas como um de seus itens. Nas demais, este assunto consta das ementas e dos programas. As bibliografias indicam que é o histórico vinculado às conferências internacionais sobre meio ambiente e ao desenvolvimento de diretrizes para a educação ambiental. Neste sentido, o histórico da Educação Ambiental tem se constituído, em muitas experiências, como ponto de partida para a estruturação de uma proposta acadêmica de 
trabalho, pois sua cronologia e os resultados das conferências internacionais apontam dados concretos sobre os objetivos e finalidades pretendidos a partir da ação educativo-ambiental.

As políticas públicas para a educação ambiental representam um item das ementas das disciplinas "Educação Ambiental" e "Fundamentos da Educação Ambiental" e estão presentes nas bibliografias das disciplinas de "Fundamentos da Educação Ambiental", "Estágio Supervisionado" e "Meio Ambiente e Educação".

Para o histórico e as políticas públicas, a bibliografia indicada, de autores como Carlos Frederico Loureiro e Gustavo Lima, contextualiza o surgimento e desenvolvimento da educação ambiental (crise ambiental, questão ambiental, problemática ambiental) e as múltiplas e complexas dimensões que compõem a relação entre a sociedade e a natureza, sobre as quais a educação ambiental encontra seus maiores desafios no sentido da mudança. Sobre as políticas públicas, não há bibliografia específica, a não ser o que se refere ao documento do PNEA. Não há referências sobre as políticas mais recentes, inclusive a estadual e a municipal. No entanto, dada a flexibilidade que impõe o processo de planejamento das ações pedagógicas, presume-se que haverá uma gradativa inserção de novos documentos de referência na execução das disciplinas.

A heterogeneidade da educação ambiental só está presente nas disciplinas "Fundamentos da Educação Ambiental", "Estágio Supervisionado" e "Meio Ambiente e Educação". Nestes casos, a bibliografia que apresenta esta heterogeneidade é também dos autores acima citados, além de Philippe Pomier Layrargues, Mauro Guimarães e outros. Alguns deles articulam os aspectos políticos e epistemológicos das diferentes possibilidades de educação ambiental ao contexto de surgimento e desenvolvimento da educação ambiental no mundo e no Brasil.

A transformação de racionalidade ou paradigma do conhecimento e a decorrente construção de novas relações entre saberes/disciplinas só não estão presentes na disciplina "Educação Ambiental" 1 e 2. Nas demais, este assunto está disperso na bibliografia sobre educação ambiental, particularmente quando a crise ambiental e sua racionalidade correspondente são apresentadas junto à proposta de construção de novas racionalidades/paradigmas, nela se destacando a questão da complexidade. Enrique Leff é referência nessas disciplinas. Edgard Morin está na bibliografia de duas disciplinas, "Estágio Supervisionado" e "Meio Ambiente e Educação" e é citado por autores da bibliografia de "Fundamentos da Educação Ambiental". Observa-se que este é o assunto mais presente na bibliografia, uma vez que ele perpassa, por exemplo, os assuntos anteriores e outras discussões sobre objetivos e metodologias da educação ambiental. Sobre a relação entre saberes e disciplinas, ainda que a relação entre saberes seja considerada por Enrique Leff, presente em quatro disciplinas, observa-se que 
somente duas delas "Estágio Supervisionado" e "Meio Ambiente e Educação" indicam bibliografia específica sobre interdisciplinaridade.

$\mathrm{O}$ assunto da mudança da relação do homem ou da sociedade com a natureza está imbricado a praticamente todos os assuntos anteriores, enquanto mudança que implica a transformação social em todas as suas dimensões: nas estruturas da sociedade capitalista, na racionalidade que a sustenta, nos valores e comportamentos, etc. Presente na bibliografia de todas as disciplinas, os discursos sobre mudança social, civilizacional, cultural, etc., está presente como finalidade da Educação Ambiental. A formação do sujeito desta mudança, através da formação do cidadão ou do sujeito ecológico, está presente, principalmente, nas bibliografias que contemplam os objetivos da Educação Ambiental crítica e emancipatória.

Ainda sobre assuntos presentes no conteúdo, observa-se que entre as disciplinas analisadas, somente duas delas, "Educação Ambiental" e "Fundamentos da Educação", tratam de assuntos como a formação de professores para a Educação Ambiental e metodologias de ensino para a Educação Ambiental. Nos currículos dos professores destas disciplinas, consta a formação e pesquisa ou a atuação na Educação Ambiental.

O perfil político-epistemológico das disciplinas indica afinidade destas com assuntos e abordagens que apresentam a Educação Ambiental contextualizada na problemática ambiental construída a partir da constatação da crise ambiental e da reconstrução da relação entre a sociedade e a natureza em todas as suas dimensões. Indica também que a complexidade e a reconstrução paradigmática do conhecimento, ou ainda a construção de um saber ambiental, é colocada como "referencial epistemológico" do conhecimento ao qual está imbricada a perspectiva de mudança social ou civilizacional.

A abordagem exploratória das disciplinas constata a presença da discussão político-epistemológica em torno da Educação Ambiental, mais afim ao seu potencial "transformador" indicado anteriormente no bojo dos argumentos apresentados neste texto. Contudo, o que está nas ementas, nos programas e bibliografias, não garante esta afinidade, assim como não garante que ela seja interpretada pelo aluno enquanto tal. Fatores subjetivos e objetivos, como a interpretação do professor do programa e da bibliografia utilizada, alterações deste programa e da bibliografia ao longo do curso, a forma como é conduzida a disciplina, assim como o resultado da apreensão desta pelos alunos, é que, de fato, determinam o resultado final da influência destas disciplinas na formação do professor para a ação educativo-ambiental. 


\section{Considerações finais}

A formação dos licenciados da UFPR conta a educação ambiental através das disciplinas sobre o tema, ofertadas para somente cinco dos 22 cursos de licenciatura. Ainda que a estrutura unidisciplinar não seja a recomendação para o trabalho com a educação ambiental, dentro do campo, foi o espaço criado pelos agentes para a educação ambiental. Identificar se o possível é relevante no que se refere à potencialização da educação ambiental na universidade, particularmente nos cursos de licenciatura, se configura na busca de alternativas viáveis para a reconfiguração do campo educativo-ambiental no âmbito das ações que se desenvolvem nas instituições de Ensino Superior. Busca que não pode desconsiderar a questão do conhecimento ambiental no contexto do campo acadêmico e os problemas de formação de professores de forma geral no Brasil, com o intuito de não desconsiderar a utopia, mas sem perder de vista as referências da realidade.

O perfil político-epistemológico das disciplinas indica a retradução da problemática ambiental para a educação ambiental, na qual prevalece o sentido de educação ambiental afim à utopia da transformação do conhecimento e da relação entre a sociedade e a natureza, considerados os fundamentos da educação ambiental propriamente ditos. Esta constatação, embora indicativa, não pode ser considerada como absoluta. Para observar a tradução realizada, efetivamente, de um conteúdo ou de uma bibliografia, outras dimensões de análise devem ser consideradas, além da pesquisa exploratória aqui apresentada. A posição dos agentes, professores que criaram e ministram as disciplinas, o contexto social e interno ao campo relacionado às pressões e solicitações que são feitas à universidade, até mesmo a posição dos cursos de licenciatura e seu valor no campo, assim como os problemas relacionados aos cursos de licenciatura, além de outras variáveis, devem ser analisadas para ampliar a compreensão do que já foi observado e para ampliar a análise da trajetória dos bens simbólicos no campo.

Por um lado, supõe-se que o contato do licenciando com as disciplinas aqui analisadas é capaz de introduzi-lo nos fundamentos da educação ambiental, no caminho do potencial transformador que ela carrega. Em duas delas, isto se completa com a preocupação de tratar também a sua dimensão didático-pedagógica. Contudo, características como carga horária, o fato de ser disciplina tradicional e o perfil dos seus professores são, por outro lado, indícios de obstáculos da formação para a educação ambiental. $\mathrm{O}$ quanto os alunos estarão capacitados para o exercício da educação ambiental no ensino básico é objeto para futuras pesquisas, o que no caso da UFPR não inspira grandes expectativas. Mas, se cabe um juízo de valor, na UFPR há um bom começo a ser potencializado. 


\section{REFERÊNCIAS}

BOURDIEU, P. Os usos sociais da ciência: Por uma sociologia do campo científico. São Paulo: Editora Unesp, 2004.

. Algumas propriedades do campo. In:

(Org.). Questões de sociologia.

Rio de Janeiro: Marco Zero, 1983. p. 89-94.

BRASIL. Ministério da Educação. Conselho Nacional de Educação/Conselho Pleno. Resolução n 2, de 15 de junho de 2012. Diretrizes Curriculares Nacionais para a Educação Ambiental. Diário Oficial da União, Brasília, DF, 2012, 5p. Disponível em: $<$ http:// mobile.cnte.org.br:8080/legislacao-externo/rest/lei/89/pdf $>$. Acesso em: 21/11/2013.

BRASIL. Secretaria de Educação Fundamental. Parâmetros curriculares nacionais: apresentação dos temas transversais/ Secretaria de Educação Fundamental. Brasília: $\mathrm{MEC} / \mathrm{SEF}, 1997.146 \mathrm{p}$.

BURSZTYN, Marcel. Meio ambiente e interdisciplinaridade: desafios ao mundo acadêmico. Desenvolvimento e Meio Ambiente, Curitiba: Editora UFPR, n. 10, p. 67-76, 2004.

CARNEIRO, Sonia M. M. Fundamentos epistemo-metodológicos da educação ambiental. Educar em Revista, Curitiba, n. 27, p. 17-36, 2006.

CARVALHO, Isabel Cristina de Moura. Educação ambiental crítica: nomes e endereçamentos da educação. In: LAYRARGUES, Philippe Pomier (Org.). Identidades da educação ambiental brasileira. Brasília: Ministério do Meio Ambiente, 2004.

CRUZ, Ricardo Gauterio; BIGLIARDI, Rosane Vinhas. Uma abordagem exploratória ao conteúdo epistemológico das Diretrizes Curriculares Nacionais para a Educação Ambiental. Revista Eletrônica do Mestrado em Educação Ambiental, Rio Grande/RS, v. 29, jul./dez. 2012. Disponível em: <http://www.seer.furg.br/remea/article/view/2845>. Acesso em: 12/12/2013.

GONZÁLEZ-GAUDIANO, Edgar. Educación para la ciudadanía ambiental. Interciencia, v. 28, n. 10, p. 611-615, 2003. Disponível em: <http://www.redalyc.org/articulo.oa?id= 33908509>. Acesso em: 20/04/2011.

GUERRA, Antonio Fernando Silveira. Ambientalização curricular e sustentabilidade na Universidade: concepções de professores e Coordenadores de cursos de graduação da Univali. In: CONGRESSO NAICONAL DE EDUCAÇÃO EDUCERE, 11., 2013, Curitiba. Anais... Curitiba, 2013. Disponível em: <educere.bruc.com.br/ANAIS2013/ pdf/13045_6588>. Acesso em: 14/02/2014.

LEFF, Enrique. Campo controversial y en incesante construcción. Entrevista con Enrique Leff Zimmerman. In: ÁRIAS ORTEGA, Miguel Angel. La construcción del campo de la educación ambiental: análisis, biografías y futuros posibles. Guadalajara, Jaleco: Editora Universitaria, 2013. 
. Complejidad, racionalidad ambiental y diálogo de saberes: hacia una pedagogía ambiental. Desenvolvimento e Meio Ambiente, Curitiba: Editora UFPR, n. 16, p. 11-20, 2007.

. Racionalidade ambiental: a reapropriação social da natureza. Rio de Janeiro: Civilização Brasileira, 2006.

LIMA. Gustavo da Costa. Educação ambiental no Brasil: formação, identidades e desafios. Campinas, SP: Papirus, 2011.

MORIN, Edgar; CIURANA, Emilio Roger; MOTTA, Raúl Domingo. Educar na era planetária: o pensamento complexo como método de aprendizagem no erro e na incerteza humana. São Paulo: Cortez; Brasília, DF: Unesco, 2003.

. O método IV: as idéias, a sua natureza, vida, habitat e organização. Mira-Sintra-Mem Martins, Portugal: Europa/América, 1992.

OLIVEIRA, Haydéee Torres de. Contextos e desafios na produção de sentidos sobre sustentabilidade e ambientalização na educação superior. In: LEME, Patrícia C. Silva et al. Visões e experiências ibero-americanas de sustentabilidade nas universidades. Desdobramentos do $3^{\circ}$ Seminário Internacional de Sustentabilidade na Universidade. São Paulo, 2011. Disponível em: <http://disciplinas.stoa.usp.br/pluginfile.php/106025/ mod_resource/content/2/texto_8.pdf>. Acesso em: 30/09/2013.

PAVESI, Alessandra; FARIAS, Carmen R. O.; OLIVEIRA, Haydée Torres. Ambientalização da Educação Superior como aprendizagem institucional. Revista ComScientia Ambiental. Curitiba, 2 sem. 2006. Disponível em: <http://www.comscientia-nimad. ufpr.br/2006/02/ acervo_cientifico/outros_artigos/artigo_sandra_pavesi.pdf $>$. Acesso em: 02/04/2014.

REDE UNIVERSITÁRIA DE PROGRAMAS DE EDUCAÇÃO AMBIENTAL PARA SOCIEDADES SUSTENTÁVEIS (RUPEA). Mapeamento da educação ambiental em instituições brasileiras de educação superior: elementos para discussão sobre políticas públicas. (2005). Disponível em: <www.reasul.org.br/mambo/files/ANEXO\%201\%20 RELATORIO_RUPEA.pdf $>$. Acesso em: 20/09/2008.

SANTOS, Boaventura de Sousa. Introdução a uma ciência pós-moderna. Rio de Janeiro, Graal, 1989.

. A universidade no século XXI: Para uma reforma democrática, emancipatória da universidade. In: ; ALMEIDA FILHO, N. (Org.). A universidade no século XXI: para uma universidade nova. Coimbra, Portugal, 2008. Disponível em: $<\mathrm{http}: / /$ www.boaventuradesousasantos.pt/media/A\%20Universidade $\% 20$ no\%20Seculo\%20 XXI.pdf $>$. Acesso em: 20/05/2011.

SAUVÉ, Lucie. Educação Ambiental: possibilidade e limitações. Educação e Pesquisa, São Paulo, v. 31, n. 2, maio/ago. 2005. Disponível em: <http://www.scielo.br/pdf/ep/ v31n2/a12v31n2>. Acesso em: 20/08/2012. 
TEIXEIRA, Cristina. Novos arranjos do conhecimento na formação acadêmica. In: CONGRESSO INTERNACIONAL DA ASSOCIAÇÃO LATIONAMERICANA DE SOCIOLOGIA, 28., 2011. Recife, 2011. Disponível em: <http://www.alas2011recife. com>. Acesso em: 3/12/2011.

THOMAZ, C. Estevão; CAMARGO, Dulce Maria Pompêo de. Educação ambiental no ensino superior: múltiplos olhares. Revista Eletrônica Mestrado em Educação Ambiental, v. 18, p. 303-318, 2007. Disponível em: <http://www.seer.furg.br/remea/article/ view/3555>. Acesso em: 20/09/2010.

TORALES, Marília Andrade. A inserção da educação ambiental nos currículos escolares e o papel dos professores: da ação escolar à ação educativo-comunitária como compromisso político-pedagógico. Revista Eletrônica do Mestrado em Educação Ambiental, Rio Grande/RS, v. especial, p. 1-17, mar. 2013. Disponível em: <http:/www.seer.furg. br/remea/ article/viewFile/3437/2064>. Acesso em: 02/02/2014.

VISÕES e experiências ibero-americanas de sustentabilidade nas universidades. Desdobramentos do $3^{\circ}$ Seminário Internacional de Sustentabilidade na Universidade. São Paulo, 2011. Disponível em: <http://disciplinas.stoa.usp.br/pluginfile.php/106025/mod_ resource/content/2/texto_8.pdf>. Acesso em: 30/09/2013.

Texto recebido em 09 de setembro de 2014. Texto aprovado em 13 de outubro de 2014. 